\title{
Determinants of asthma phenotypes in supermarket bakery workers
}

\author{
R. Baatjies*,\#, A.L. Lopata ${ }^{\uparrow,+}$, I. Sander ${ }^{\S}$, M. Raulf-Heimsoth ${ }^{\S}$, E.D. Bateman ${ }^{f}$, \\ T. Meijster**,\#\#, D. Heederik ${ }^{\# \#}$, T.G. Robins ${ }^{\text {ฯฯ }}$ and M.F. Jeebhay*
}

ABSTRACT: While baker's asthma has been well described, various asthma phenotypes in bakery workers have yet to be characterised. Our study aims to describe the asthma phenotypes in supermarket bakery workers in relation to host risk factors and self-reported exposure to flour dust.

A cross-sectional study of 517 supermarket bakery workers in 31 bakeries used a questionnaire, skin prick tests, and specific immunoglobulin $\mathrm{E}$ to wheat, rye and fungal $\alpha$ amylase and methacholine challenge testing.

The prevalence of probable occupational asthma (OA, 13\%) was higher than atopic (6\%), nonatopic (6\%) and work-aggravated asthma (WAA, 3\%) phenotypes. Previous episodes of high exposure to dusts, fumes and vapours causing asthma symptoms were more strongly associated with WAA (OR 5.8, 95\% CI 1.7-19.2) than OA (2.8, 1.4-5.5). Work-related ocular-nasal symptoms were significantly associated with WAA $(4.3,1.3-13.8)$ and OA $(3.1,1.8-5.5)$. Bakers with OA had an increased odds ratio of reporting adverse reactions to ingested grain products $(6.4,2.0-19.8)$.

$\mathrm{OA}$ is the most common phenotype among supermarket bakery workers. Analysis of risk factors contributes to defining clinical phenotypes, which will guide ongoing medical surveillance and clinical management of bakery workers.

KEYWORDS: Asthma phenotypes, bakery workers, determinants, risk factors, work-related asthma

$\mathrm{t}$ is well documented that exposure to flour dust increases the risk of respiratory diseases, particularly occupational asthma (OA). Studies conducted among bakery workers have reported the prevalence of baker's asthma to be $5-17 \%$ [1]. Asthma is commonly due to sensitisation to wheat, rye and fungal $\alpha$-amylase allergens present in flour.

Asthma is generally not considered to be a single disease but rather a syndrome comprising a common set of symptoms. Different phenotypes of asthma are distinguished by variations in clinical features, trigger factors and differences in immunological and pathophysiological characteristics [2]. Age of onset, high numbers of eosinophils in the airways, atopic status, family history of asthma, early exposure to allergens and exposure to inhalation accidents (exposure to high levels of vapours, gas, dust or fumes) are important predictors of adult asthma phenotypes [2, 3]. While baker's asthma has been well described in various workplaces, phenotypes of asthma among bakery workers in a common workplace setting have yet to be characterised.

An evaluation of employment patterns in the baking industry worldwide over the past decade has demonstrated a significant rise in franchise (in-store) bakeries [4]. In South Africa, in-franchise employment has risen from $20 \%$ of all employment in the baking industry in 1995 to $44 \%$ in 2002 [5]. This shift has increased the potential for workers to develop baker's allergy and asthma.

The aim of our study is to describe various asthma phenotypes observed in supermarket bakery workers of a large chain store in relation to host risk factors and self-reported exposures to flour dust.

Our study is part of a larger prospective intervention study aimed at reducing sensitisation to flour dust allergens in supermarket bakers. A detailed baseline environmental exposure assessment study was also conducted and is the subject of a separate communication.

\section{MATERIALS AND METHODS}

\section{Study design, population and sampling}

A cross-sectional study was conducted on 517 workers currently employed in all 31 bakeries belonging to a supermarket chain store in the Western Cape province of South Africa during

\section{AFFILIATIONS}

*Centre for Occupational and Environmental Health Research Unit, School of Public Health and Family Medicine, University of Cape Town,

"Division of Immunology, IIDMM,

Faculty of Health Sciences,

University of Cape Town

fUniversity of Cape Town Lung Institute,

${ }^{\#}$ Dept of Environmental and Occupational Studies, Faculty of Applied Sciences, Cape Peninsula University of Technology, Cape Town South Africa,

${ }^{+}$Royal Melbourne Institute of Technology, Allergy Research Group, Melbourne, Australia.

${ }^{\S}$ BGFA - Research Institute of Occupational Medicine, German Social Accident Insurance, Ruh University Bochum, Bochum, Germany.

**Dept of Food and Chemical Risk Analysis, TNO Quality of Life, Zeist,

\#\# Institute for Risk Assessment Sciences, Utrecht University, Utrecht The Netherlands.

"Dept of Environmental Health Sciences, University of Michigan, Ann Arbor, MI, USA.

CORRESPONDENCE

M.F. Jeebhay, Centre for Occupational and Environmental Health Research Unit, School of Public Health and Family Medicine, University of Cape Town, Room 4.44, Fourth Level, Falmouth Building, Anzio Road, Observatory, 7925 South Africa

E-mail: Mohamed.Jeebhay@ uct.ac.za

Received:

Oct 302008

Accepted after revision: March 122009

First published online: May 142009

European Respiratory Journal Print ISSN 0903-1936 Online ISSN 1399-3003 
the period June 2003 to June 2004. All permanent $(n=318)$ and casual workers $(n=168)$ in the bakery and ex-bakers with asthma moved from the bakery section 2 yrs prior to our study $(n=31)$ were investigated. The protocol was approved by the University of Cape Town (Cape Town, South Africa) and the Institutional Review Board of the University of Michigan (Ann Arbour, MI, USA) prior to the study being conducted.

\section{Questionnaire}

Each worker completed the standard European Community Respiratory Health Survey (ECRHS) questionnaire [6] designed for the investigation of asthma. Additional questions relating to current and previous employment and degrees of exposure to flour dust and tobacco smoke were included. Smoking status was classified into the following three categories: never-smoker (lifelong abstinence), ex-smoker (defined as having quit completely $>1$ month prior to the survey) and current smoker. Self-reported high exposures were ascertained based on a positive response to the question: "Has there ever been an instance when you inhaled a large amount of vapour, gas, dust or fumes in any of these jobs that resulted in you developing a tight chest, wheeze or cough?". Also included were questions on domestic flour dust exposures and, in particular, the practice and frequency of baking activities in the home. For the purposes of our study, ocular-nasal symptoms were defined as a positive response to the question: "Have you ever had any nose or eye problems or allergies such as hay fever?". Upper and lower airway symptoms were considered to be work-related if they were reported to worsen during the work shift and improve when away from work. Ingestion-related adverse reactions were assessed based on responses to the question: "Have you changed your diet or avoided certain grain products (e.g. wheat/rye/soya) because they do not agree with you when you eat them?".

\section{Immunological tests}

\section{Skin prick tests}

Skin prick tests (SPTs) were performed using the following standard common local aeroallergens (ALK-Abelló A/S, Horsholm, Denmark): house dust mite (Dermatophagoides pteronyssinus), bermuda grass (Cynodon dactylon), rye grass (Lolium perenne), grass mix (Pollen III: Avena, Hordeum, Triticum, Secale), cockroach (Blattella germanica), cat (Felis domesticus), dog (Canis familiaris), mould mix (Cladosporium herbarum, Alternaria alternata, Fusarium) and Aspergillus (Aspergillus fumigatus). Commercially available SPTs of flours (wheat, rye, oat grain and barley grain) (Bencard, Neuss, Germany), soya and corn flour (Leti Alergia, Madrid, Spain), peanut and storage mite (Lepidoglyphus destructor), and fungal $\alpha$-amylase (ALK-Abelló) were also used. For the analysis of correlations between various allergens, SPT reactivity was expressed as the allergen histamine wheal ratio, i.e. the mean wheal diameter at the allergen site divided by the mean wheal diameter at the histamine site [7]. A positive SPT was regarded as a wheal read $15 \mathrm{~min}$ after testing that had a diameter (mean of two perpendicular measures) of $\geqslant 3 \mathrm{~mm}$ more than the negative control. Areas of wheal were traced on clear tape and stored for later measurement. For the purposes of our study, atopy was considered to be present if the SPT to one or more common aeroallergens was positive.

\section{Serum-specific immunoglobulin E}

Serum-specific immunoglobulin (Ig) E levels were measured in 513 workers. The presence of atopy in workers who did not undergo SPTs $(n=10)$ was defined by a positive Phadiatop ${ }^{\circledR}$ test (ImmunoCAP 100 System; Phadia, Uppsala, Sweden). Quantification of specific IgE antibodies to wheat (f4), rye (f5) and fungal $\alpha$-amylase (k87) was performed using CAP-FEIA (fluorescence enzyme immunoassay) according to the manufacturer's instructions (Phadia). An ImmunoCAP result of $>0.35 \mathrm{kU} \cdot \mathrm{L}^{-1}$ was regarded as positive.

\section{Spirometry}

Spirometry was performed using the Jaeger Aerosol Provocation System (APS) Pro apparatus according to American Thoracic Society guidelines [8]. Workers were required to refrain from smoking for $1 \mathrm{~h}$, from using short-acting $\beta_{2}$-agonist bronchodilators for $4 \mathrm{~h}$, and from using oral asthma medications for $8 \mathrm{~h}$ prior to lung function testing. None were on long-acting bronchodilators. Pulmonary function reference values of the European Community for Coal and Steel with lower limits corresponding to the 95th percentile were used where appropriate, and the locally derived reference equation for South African university workers was applied $[9,10]$.

\section{Methacholine challenge testing}

Methacholine challenge testing was performed on all workers by trained technologists according to an abbreviated protocol used in epidemiological surveys. The Medic Aid Pro Nebulizer dosimeter method involved a protocol of increasing numbers of breaths to achieve pre-defined cumulative doses of methacholine [11]. The doses were delivered by the Jaeger APS MedicAid Side Stream APS-Nebulizer (Sensormedics, CA, USA) according to the manufacturer's instructions, commencing with the lowest dose of $0.026 \mathrm{mg}$. The dose was increased to a maximum dose of $2.048 \mathrm{mg}$ methacholine (the provocative dose of methacholine causing $a \geqslant 20 \%$ fall in forced expiratory volume in $1 \mathrm{~s}$ (FEV1); PD20 methacholine) if a positive endpoint was not obtained. The results of the methacholine challenge test were interpreted as follows: borderline $=0.4 \mathrm{mg}$ $<$ PD20 methacholine $<1.0 \mathrm{mg}$; mild $=0.08 \mathrm{mg}>$ PD20 methacholine $<0.4 \mathrm{mg}$; moderate/severe $=$ PD20 methacholine $<0.08 \mathrm{mg}$. Borderline values for PD20 methacholine were considered negative in the definition of nonspecific bronchial hyperresponsiveness (NSBH). These cut-offs for the APS system were based on the results from a validation study performed on 40 hyperresponsive bakery workers. This study confirmed a satisfactory correlation between the APS cumulative PD20 methacholine method and the standard VMAX (Sensormedics) method [11].

In subjects in whom PD20 methacholine was contraindicated, such as those with acute asthma symptoms or a baseline FEV1 $<1.5 \mathrm{~L}$ or FEV1 $<70 \%$ predicted, a bronchodilator $(400 \mu \mathrm{g}$ salbutamol dose) was administered instead. A change in FEV1 of $\geqslant 12 \%$ pred $10 \mathrm{~min}$ after administration of bronchodilator was considered suggestive of NSBH.

Among the 503 subjects who underwent normal spirometry, 422 performed interpretable PD20 methacholine results. Two subjects were unable to produce reproducible FEV1 manoeuvres, 38 subjects underwent bronchodilator challenge (postbronchodilator), since PD20 methacholine was contraindicated, 
and 43 subjects had $\geqslant 10 \%$ decrease in FEV1 after administration of saline diluent, and were therefore not considered for PD20 methacholine. The PD20 methacholine was discontinued in three subjects; one requested the test to be stopped, and in two subjects the test was stopped because of technical problems.

\section{Operational definitions of asthma phenotypes}

Atopic asthma (AA) was defined as either having an asthma attack or use of asthma medication in the past 12 months or presence of NSBH, the presence of atopy, and the absence of sensitisation to bakery dust allergens [3].

Nonatopic asthma (NAA) was defined as either having an asthma attack or use of asthma medication in the past 12 months or the presence of NSBH, being nonatopic, and the absence of sensitisation to bakery dust allergens.

Work-aggravated asthma (WAA) was defined as either having an asthma attack or use of asthma medication in the past 12 months or the presence of NSBH, work-related chest symptoms, and the absence of sensitisation to bakery dust allergens.

Probable occupational asthma was defined as either having an asthma attack or use of asthma medication in the past 12 months or the presence of NSBH, and sensitisation to bakery dust allergens [12].

Sensitivity to bakery dust allergens was defined as either a positive SPT to any cereal allergen (wheat, rye, oats, barley, soya or corn) or elevated serum IgE to wheat, rye or $\alpha$-amylase.

\section{Statistical analysis}

Statistical analysis was performed using STATA version 8 (StataCorp, College Station, TX, USA). Both continuous and categorical analyses were conducted. Key associations of interest were the relationships between host factor attributes (e.g. age, sex, smoking, past medical history, ingestion-related reactions to grain products and adult-onset asthma), and selfreported occupational exposures with asthma phenotypes. Multivariate logistic regression models adjusted for age, sex and smoking were used to determine the relationship between individual asthma phenotypes and predictor variables.

\section{RESULTS}

\section{Study population}

A total of 517 workers from all 31 stores participated in our study. The demographic characteristics of the study population are outlined in table 1 . Almost half the participants (47\%) were current smokers, with an average of 5 pack-yrs smoking history. Of the currently employed workers, $41 \%$ were bakers or assistant bakers, $27 \%$ counterhands and $10 \%$ confectioners. Among the workers with self-reported adverse reactions to grain products, a larger proportion (63\%) attributed this to rye products.

\section{Immunological characteristics}

The prevalence of sensitisation to common inhalants were as follows: house dust mite (D. pteronyssinus), 33\%; rye grass ( $L$. perenne), 20\%; grass mix (Pollen III), 18\%; cockroach (B. germanica), $11 \%$; bermuda grass (C. dactylon), 10\%; dog (C. familiaris), $8 \%$; mould mix (Cladosporium, A. alternate, Fusarium), $7 \%$; cat
(F. domesticus), 4\%; and aspergillus (A. fumigatus), 3\%. The overall prevalence of atopy, defined as a positive SPT to one or more common aeroallergens, was $42 \%$, while $12 \%$ were positive to more than three aeroallergens. The prevalence of sensitisation to any of the bakery dust allergens was 33\% (table 2). The most common sensitisers on SPT were cereal flours wheat $(16 \%)$ and rye $(16 \%)$. However, higher proportions of workers (26 and $24 \%$ to wheat and rye flours, respectively) had elevated IgE levels to flours, but the prevalence of elevated $\operatorname{IgE}$ to $\alpha$-amylase remained low $(4 \%)$. A high degree of correlation was found for subjects sensitised to a number of the various cereal flours, especially wheat, rye, barley and corn flour (Spearman's $r=0.67-0.75$, $\mathrm{p}<0.001)$. Comparison of wheat SPT versus wheat IgE, as well as rye SPT versus rye IgE, showed a high degree of correlation (Spearman's $r=0.71-0.73, \mathrm{p}<0.0001$ ) between these two indices of allergic sensitisation with the kappa statistic demonstrating

\section{TABLE 1 Demographic characteristics of supermarket bakery workers}

Demographic characteristics

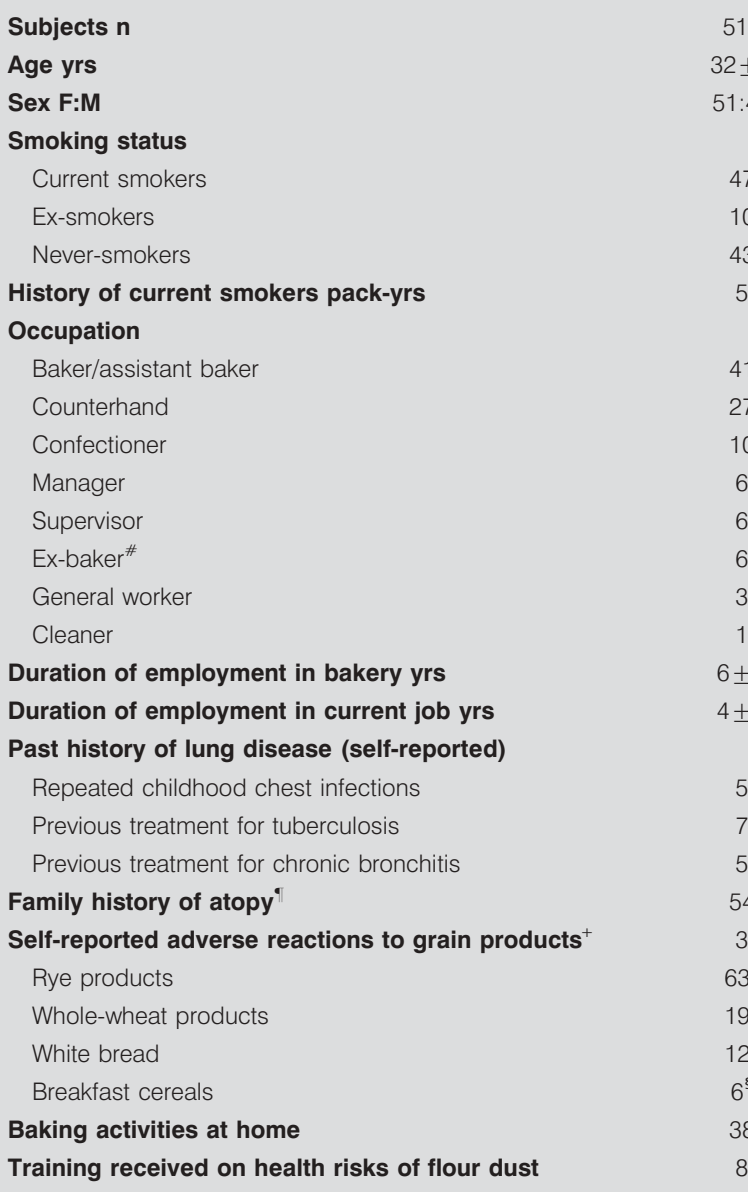

Data are presented as $\%$ or mean $\pm \mathrm{SD}$, unless otherwise indicated. F: female M: male. " : removed from the bakery in the last 2 yrs due to baker's asthma; defined as positive answer to the question "Does any member of your family (blood relatives) have any kind of allergies (e.g. hay fever, eczema, asthma)?" $+: n=16 ;{ }^{\circledR}$ : as a proportion of the sub-group $(n=16)$ 
TABLE 2 Allergic sensitisation profiles for potential occupational allergens among supermarket bakery workers

Occupational allergen
Allergic sensitisation profiles

\begin{tabular}{ccc}
\hline Overall & Atopic & Nonatopic \\
507 & 213 & 294 \\
$79(16)$ & $52(24)$ & \\
$82(16)$ & $55(26)$ & $27(9)$ \\
$73(14)$ & $51(24)$ & $27(9)$ \\
$59(12)$ & $40(19)$ & $22(7)$ \\
$42(8)$ & $32(15)$ & $19(6)$ \\
$41(8)$ & $31(15)$ & $10(3)$ \\
$73(14)$ & $67(31)$ & $10(3)$ \\
$30(6)$ & $28(13)$ & $6(2)$ \\
$17(3)$ & $13(6)$ & $2(1)$ \\
$134(26)$ & & $4(1)$ \\
$123(24)$ & $90(42)$ & $44(15)$ \\
$21(4)$ & $81(38)$ & $42(14)$ \\
$172(33)$ & $15(7)$ & $6(2)$ \\
& $113(52)$ & $59(20)$
\end{tabular}
94
$22(7)$
$9(6)$
$0(3)$
$10(3)$
$(2)$
(14)
$59(20)$

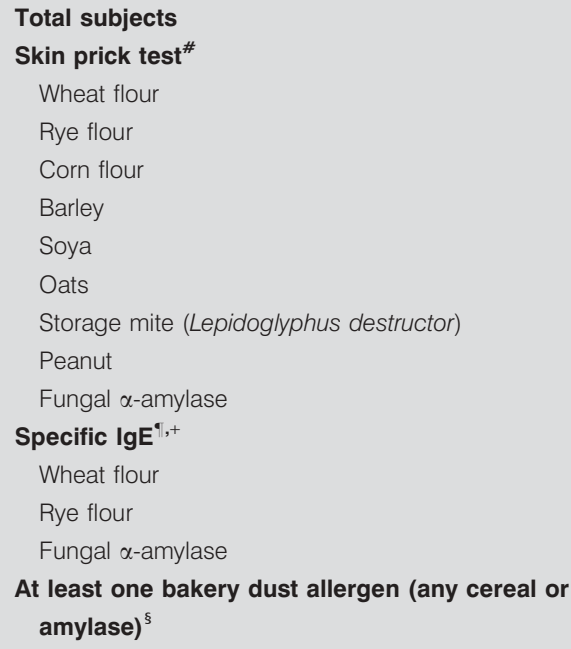

At least one bakery dust allergen (any cereal or amylase) $^{\text {s }}$

Data are presented as $\mathrm{n}$ and $\mathrm{n}(\%)$. Each result represents sensitisation to an individual allergen, with some workers sensitised to more than one allergen. Ig:

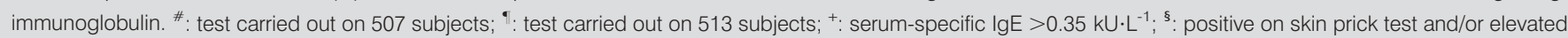
IgE. Note: Chi-squared test between atopic versus nonatopics significant $(p<0.0001)$ for all allergens, except for fungal $\alpha$-amylase $(p<0.01)$.

moderate to substantial agreement $($ kappa $=0.55-0.64)$ between the tests. Workers sensitised to more than three aeroallergens were more likely to be sensitised to occupational allergens (OR 9.5, 95\% CI 4.9-18.2).

\section{Respiratory symptoms}

The prevalence of work-related ocular-nasal symptoms (31\%) was higher than work-related chest symptoms (17\%; table 3$)$. Over half the workers with doctor-diagnosed asthma (13\%) reported adult-onset asthma, and $38 \%$ of these reported current ocular-nasal symptoms. $30(6 \%)$ workers reported job changes prompted by work-related chest symptoms. Of these, 14 had worked as bakers/assistant bakers, 10 as counterhands, four as confectioners and two as a supervisor/controller prior to being relocated. A significantly higher proportion of females had shortness of breath $(10 \%)$, current asthma treatment or attacks $(9 \%)$, but a lower proportion $(8 \%)$ reported symptoms associated with episodes of high exposure to flour dust. An evaluation of the sensitivity and specificity of the questionnaire to predict asthma and, more specifically, OA revealed that work-related chest symptoms were highly specific $(89 \%)$ for both outcomes, but were not very sensitive (31-43\%) in accurately predicting the presence of NSBH and OA, respectively.

\section{Pulmonary function and NSBH}

The results of pulmonary function and nonspecific bronchial challenge tests are presented in table 4. Using European Community of Coal and Steel reference values, $17 \%$ of workers had an FEV1 of $<80 \%$ pred, while only $7 \%$ had evidence of airflow obstruction defined as a pre-bronchodilator FEV1/forced vital capacity (FVC) ratio of $<0.70$. Using an alternative set of reference values according to WHITE et al. [10], the prevalence of FEV $1<80 \%$ pred was $9 \%$. A total of $22 \%$ of workers had evidence of bronchial hyperresponsiveness (19\% positive on the methacholine challenge test (PD20 methacholine $<0.4 \mathrm{mg})$ ), and 3\% positive on the basis of an increase in FEV1 of $\geqslant 12 \%$ after

\section{TABLE 3 Upper and lower respiratory symptoms among supermarket bakery workers}

\begin{tabular}{lc} 
Symptom & Prevalence \\
\hline $\begin{array}{l}\text { Subjects } \mathbf{n} \\
\text { Asthma history }\end{array}$ & 517 \\
$\quad$ Doctor-diagnosed asthma & $67(13)$ \\
$\quad<17$ yrs & $30(6)$ \\
$\quad \geqslant 17$ yrs & $37(7)$ \\
$\quad$ Current use of asthma medication & $36(7)$ \\
$\quad$ Asthma attack in the past year & $31(6)$ \\
Work-related asthma symptoms & \\
$\quad$ Episode of high exposure causing tight chest, wheeze & $67(13)$ \\
$\quad$ or cough & \\
$\quad$ Work-related chest symptoms & $86(17)$ \\
$\quad$ Job change due to work-related chest symptoms & $30(6)$ \\
Upper airway symptoms & $196(38)$ \\
$\quad$ Ocular-nasal symptoms & $162(31)$ \\
$\quad$ Work-related ocular-nasal symptoms &
\end{tabular}

Data are presented as $\mathrm{n}(\%)$, unless otherwise indicated. 
bronchodilator), with a further $10 \%$ having "borderline" results (PD20 methacholine $\geqslant 0.4 \mathrm{mg}$ and $<1.0 \mathrm{mg}$ ).

\section{Correlation between lung function and wheat and rye- specific IgE}

There was a significant negative correlation between PD20 methacholine and IgE levels with wheat (Spearman $r=-0.30$, $\mathrm{p}<0.001$ ) and rye (Spearman $\mathrm{r}=-0.28, \mathrm{p}<0.001)$ flour. Stratifying the $\operatorname{IgE}$ data by atopic status revealed similar inverse relationships between PD20 methacholine and IgE among atopics (Spearman $\mathrm{r}=-0.26, \mathrm{p}<0.001$ ) and nonatopics (Spearman $r=-0.21, p<0.001)$ for wheat and rye. The degree of airway obstruction on baseline spirometry (FEV1/FVC) was also inversely correlated with wheat $\operatorname{IgE}$ (Spearman $\mathrm{r}=-0.15$, $\mathrm{p}=0.001)$. However, no correlation was observed between FEV1 and wheat-specific IgE (Spearman $r=-0.07, p=0.090$ ). Similar patterns of association were observed for rye flour (data not shown).

\section{Asthma phenotypes in relation to risk factors}

Among the asthma phenotypes described, the prevalence of probable OA (13\%) was much higher than AA $(6 \%)$, NAA $(6 \%)$ and WAA (3\%) phenotypes (table 5). A large proportion (55 $(92 \%)$ out of 60$)$ of workers with OA had NSBH, whilst only 55 $(12 \%)$ workers showed evidence of occupational rhinitis without asthma. In the multivariate logistic regression analysis, having recurrent chest infections as a child (OR 5.5) was significantly associated with WAA. Elevated odds ratios were demonstrated for the associations between atopy and OA, particularly in individuals with polysensitisation to common aeroallergens. Previous episodes of high exposure that caused asthma symptoms were associated more strongly with WAA (OR 5.8) than probable OA (OR 2.8). Those with OA were significantly more likely to be supervisors or managers
(OR 4.0) at the time of the study. There was a six-fold increased odds (OR 6.4) of self-reported ingestion-related adverse reactions to grain products in OA, and more so in the NAA subgroup. No association was found with baking at home and any of the asthma phenotypes. Using alternative definitions for probable OA, which included subjective work-related symptoms in this definition decreased the prevalence to $7 \%$. However, the significant association with predictors of this phenotype persisted and demonstrated higher odds ratios for ocular-nasal symptoms (OR 13.0), previous episodes of high exposure causing asthma symptoms (OR 5.0), as well as selfreported ingestion-related adverse reactions to grain products (OR 13.3).

\section{DISCUSSION}

This study of supermarket bakeries provides a useful insight into the relative prevalence of and risk factors for different phenotypes of asthma among workers in this emerging and relatively poorly regulated industry. Asthma phenotypes were defined on the basis of clinical asthma, airway hyperresponsiveness, atopic status and sensitisation to occupational allergens. This study has demonstrated that the prevalence of probable OA $(13 \%)$ in the industry is considerably higher than that of both AA $(6 \%)$ and NAA $(6 \%)$ and the WAA phenotype $(3 \%)$. Furthermore, the overall prevalence of AA in this cohort is at the lower end of the spectrum of adult asthma reported in developed countries (8-12\%), but higher than the national average reported for South Africa $(4 \%)[13,14]$. The higher prevalence of asthma observed in this group may be attributed to these bakeries being located in a highly urbanised province (Western Cape), which has a higher population prevalence $(8 \%)$ of adult asthma [15]. This study also demonstrated that $50 \%$ of the adult asthma phenotype is atopic, as has been reported in previous studies [16].

TABLE 4 Pulmonary function indices among supermarket bakery workers

\begin{tabular}{|c|c|c|c|c|}
\hline Pulmonary function indices ${ }^{\#}$ & Overall & Males & Females & p-value \\
\hline Subjects $\mathrm{n}$ & 503 & 243 & 260 & \\
\hline FEV $_{1} \mathrm{~L}$ & $3.16 \pm 0.77$ & $3.63 \pm 0.71$ & $2.72 \pm 0.52$ & \\
\hline FVC L & $3.83 \pm 0.88$ & $4.45 \pm 0.71$ & $3.25 \pm 0.57$ & \\
\hline FEV $_{1} \%$ pred & $92 \pm 14$ & $91 \pm 14$ & $93 \pm 14$ & $0.002^{++}$ \\
\hline FVC \% pred & $95 \pm 13$ & $94 \pm 12$ & $97 \pm 13$ & $0.055^{++}$ \\
\hline FEV $1 /$ FVC & $83 \pm 9$ & $81 \pm 10$ & $84 \pm 8$ & $0.019^{++}$ \\
\hline $\mathrm{FEV}_{1} / \mathrm{FVC}<\mathbf{7 0} \% \mathrm{n}$ & $33(7)$ & $20(8)$ & $13(5)$ & $0.144^{\S \S}$ \\
\hline FEV $1<\mathbf{8 0} \%$ pred $\mathbf{n}$ & $84(17)$ & $42(17)$ & $42(16)$ & $0.107^{\S \S}$ \\
\hline FEV $_{1}<\mathbf{8 0} \%$ pred $^{*} \mathbf{n}$ & $43(9)$ & $25(10)$ & $18(7)$ & $0.177^{\S \S}$ \\
\hline \multicolumn{5}{|l|}{ Bronchial hyperresponsiveness $n$} \\
\hline$\geqslant 12 \%$ FEV 1 increase post-bronchodilator ${ }^{+}$ & $16(3)$ & $7(3)$ & $9(3)$ & $0.086^{\S \S}$ \\
\hline$\geqslant 10 \%$ FEV 1 decrease post-saline diluent ${ }^{\S}$ & $43(9)$ & $18(7)$ & $25(10)$ & $0.269^{\S \S}$ \\
\hline Methacholine challenge test PD20 methacholine $<0.4 \mathrm{mg}^{f}$ & 94 (19) & $37(15)$ & 57 (22) & $0.012^{\S \S}$ \\
\hline $\mathrm{NSBH}^{\# \#, \bullet}$ & $110(22)$ & $44(18)$ & $66(25)$ & $0.030^{\S \S}$ \\
\hline
\end{tabular}

Data are presented as mean \pm sd or $n(\%)$, unless otherwise indicated. FEV1: forced expiratory volume in $1 \mathrm{~s}$; FVC: forced vital capacity; \% pred: \% predicted; PD20 methacholine: provocative dose of methacholine causing a $\geqslant 20 \%$ fall in FEV1; NSBH: nonspecific bronchial hyperresponsiveness. ${ }^{*}$ : pre-bronchodilator values, unless

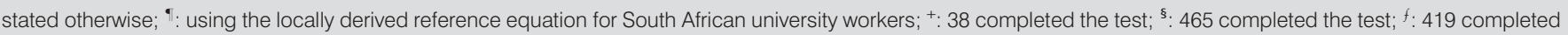
the test; ${ }^{\# \#}: 457$ completed the test; ${ }^{~}{ }^{\prime}$ : NSBH defined as any of the following two criteria: PD20 methacholine $<0.4$ or $\geqslant 12 \%$ increase in FEV 1 after administration of a bronchodilator; ${ }^{++}$: two-sample unpaired t-test; ${ }^{\text {ss. }}$ : Chi-squared test with one degree of freedom. 
TABLE 5 Risk factors associated with asthma phenotypes among supermarket bakery workers in multivariate models

\begin{tabular}{|c|c|c|c|c|c|c|}
\hline & AA & NAA & WAA & Probable OA & Atopic & Nonatopic \\
\hline Prevalence & $29(6)^{\#}$ & $29(6)^{\#}$ & $13(3)^{\#}$ & $60(13)^{\#}$ & $42(22)^{\circ}$ & $18(7)^{+}$ \\
\hline \multicolumn{7}{|l|}{ Determinants } \\
\hline Family history of asthma & $1.53(0.55-4.26)$ & $0.76(0.22-2.65)$ & $1.91(0.50-7.33)$ & $1.06(0.49-2.28)$ & $0.95(0.37-2.42)$ & $0.95(0.20-4.43)$ \\
\hline \multicolumn{7}{|l|}{ Past medical history } \\
\hline $\begin{array}{l}\text { Childhood onset } \\
\text { (<17 yrs) asthma }\end{array}$ & $2.20(0.68-7.11)$ & $1.81(0.49-6.75)$ & $2.75(0.54-13.95)$ & $2.13(0.81-5.62)$ & $2.08(0.69-6.27)$ & \\
\hline Pulmonary tuberculosis & $0.57(0.07-4.46)$ & $2.06(0.64-6.62)$ & $4.07(0.99-16.64)$ & $1.92(0.77-4.79)$ & $2.90(0.80-10.51)$ & $1.53(0.31-7.51)$ \\
\hline Chronic bronchitis & $1.81(0.39-8.40)$ & $2.59(0.69-9.74)$ & $4.47(0.89-22.49)$ & $2.01(0.71-5.70)$ & $1.94(0.46-8.22)$ & $2.44(0.46-12.84)$ \\
\hline \multicolumn{7}{|l|}{ Upper airway symptoms } \\
\hline Ocular-nasal symptoms & $2.44(1.12-5.29)^{*}$ & $0.51(0.21-1.25)$ & $2.91(0.92-9.20)$ & $6.02(3.26-11.11)^{\star \star *}$ & $4.48(1.97-10.23)^{\star \star *}$ & $7.11(2.39-21.09)^{\star \star \star}$ \\
\hline $\begin{array}{l}\text { Work-related ocular-nasal } \\
\text { symptoms }\end{array}$ & $1.56(0.72-3.39)$ & $0.73(0.30-1.78)$ & $4.30(1.34-13.77)^{\star}$ & $3.13(1.78-5.49)^{\star \star \star}$ & $2.51(1.21-5.19)^{*}$ & $3.53(1.27-9.81)^{*}$ \\
\hline $\begin{array}{l}\text { Age of first exposure to } \\
\text { flour dust allergens }\end{array}$ & $1.16(1.01-1.33)^{*}$ & $0.99(0.91-1.09)$ & $1.01(0.89-1.16)$ & $1.00(0.94-1.07)$ & $0.99(0.92-1.08)$ & $1.00(0.91-1.10)$ \\
\hline $21-30 \mathrm{yrs}^{\S}$ & $1.93(0.70-5.31)$ & $1.64(0.56-4.82)$ & $8.66(0.97-77.28)$ & $1.04(0.51-2.12)$ & $1.08(0.45-2.62)$ & $1.23(0.28-5.42)$ \\
\hline$>30$ yrs & $3.09(0.51-18.71)$ & $1.72(0.34-8.78)$ & $1.30(0.05-34.96)$ & $0.65(0.20-2.04)$ & $0.46(0.10-2.22)$ & $0.99(0.13-7.59)$ \\
\hline $\begin{array}{l}\text { Previous episodes of high } \\
\text { exposure causing asthma } \\
\text { symptoms }\end{array}$ & $1.43(0.51-4.00)$ & $2.33(0.87-6.22)$ & $5.77(1.74-19.15)^{\star \star}$ & $2.80(1.43-5.52)^{\star \star}$ & $2.70(1.07-6.83)^{\star}$ & $3.61(1.15-11.30)^{\star}$ \\
\hline \multicolumn{7}{|l|}{ Current job status $^{f}$} \\
\hline Baker & $0.37(0.11-1.18)$ & $0.50(0.17-1.46)$ & $0.10(0.01-1.18)$ & $1.57(0.66-3.74)$ & $2.14(0.78-5.88)$ & $1.68(0.14-20.77)$ \\
\hline
\end{tabular}

Data are presented as $n(\%)$ or OR (95\% CI). AA: atopic asthma; NAA: nonatopic asthma; WAA: work-aggravated asthma; OA: occupational asthma. ${ }^{\#}$ : out of a total of

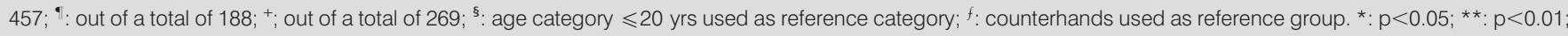
***: $p<0.001$. Each odds ratio is a separate regression model adjusted for age, sex and smoking status.

The prevalence of probable OA $(13 \%)$ in our study is at the upper end of the range of prevalence data $(5-13 \%)$ reported by studies in industrial bakeries in which a similar definition of $\mathrm{OA}$ (bronchial hyperresponsiveness and sensitivity to flour) was used $[17,18]$. However, the prevalence was much higher than that reported among British supermarket bakery workers (4\%), even after using an alternative definition that included workrelated asthma symptoms (7\%) [4]. The potential underestimation that could arise due to the healthy-worker effect was partially minimised in our study by the inclusion of ex-bakers in the study population. It should be noted that the inability to characterise the acute onset irritant-induced asthma phenotype in this study can be attributed to its low incidence in this setting as the production process in these bakeries mainly entails exposure to high molecular weight respiratory sensitisers in flour dust, although exposure to cleaning agents cannot be totally excluded [3].
In our study. a high proportion (22\%) of bakery workers demonstrated NSBH. Females, had a significantly higher prevalence than males ( $25 \%$ versus $18 \%$ ), which is consistent with previous studies in which females comprised the major proportion of study subjects [19]. Given that a greater proportion $(62-94 \%)$ of males were employed in the more highly exposed jobs (i.e. baker, confectioner, manager) and females $(98 \%)$ in the less-exposed jobs (i.e. counterhands), it is unlikely that the discrepancies observed are due to different job hiring practices for males and females. This distribution of work according to sex does not totally explain the different patterns of NSBH observed in our study, suggesting that other biological factors may play a role in the patterns observed [20].

It is well recognised that the most common flour dust allergens responsible for sensitisation in the OA phenotype among bakers 
are cereal flours and synthetic enzymes [1]. This sensitisation pattern has also been observed in the current study, in which sensitisation to wheat, rye and other related cereal flours on SPT was high $(16 \%)$, but less so for fungal enzyme $\alpha$-amylase (4\%). Preliminary data from the detailed exposure assessment study that was conducted confirmed that bakers had the highest average (geometric mean) wheat allergen concentration $\left(16.504 \mu \mathrm{g} \cdot \mathrm{m}^{-3}\right)$, followed by confectioners $\left(7.307 \mu \mathrm{g} \cdot \mathrm{m}^{-3}\right)$, whilst counterhands had the lowest exposures $\left(0.84 \mu \mathrm{g} \cdot \mathrm{m}^{-3}\right)$. However, for most job titles, $\alpha$-amylase concentrations were below the limit of detection $\left(1.083 \mathrm{ng} \cdot \mathrm{m}^{-3}\right)$. While sensitisation to cereal flours were highly correlated $(\mathrm{r}=0.67-0.75)$, a very high degree of correlation $(\mathrm{r}=0.92)$ was observed between wheat and rye. Interestingly, a large proportion $(33 \%)$ of workers reported work-related asthma symptoms specifically to rye flour, despite this flour constituting a small proportion $(<10 \%)$ of products handled in these bakeries. It has been suggested that crossreactivity between grain cereal allergens could be a possible mechanism for these observations [21]. Cross-reactivity between rye flour allergens and rye grass allergens remains another possibility, although this is unlikely as a very low correlation was observed between sensitisation to these allergens $(\mathrm{r}=0.37)$. While the response to rye may be immunologically mediated, the physical properties of rye flour may also produce an additional irritative effect, as demonstrated by its ability to produce a greater bronchial response compared with wheat [22].

In our study, a modest inverse correlation was demonstrated between PD20 methacholine and specific IgE levels to wheat (Spearman $\mathrm{r}=-0.30 ; \mathrm{p}<0.001$ ) and rye flour (Spearman $r=-0.28 ; p<0.001)$ that, as far as we can establish, has not been previously reported. However, there have been a few epidemiological studies among bakers that have reported an association between other markers of exposure (flour dust) and the degree of NSBH following nonspecific challenge tests using methacholine. PRICHARD et al. [23] reported that $41 \%$ of bakers versus $21 \%$ of controls (slicers/wrappers) had a positive methacholine challenge test (PD20 methacholine $<30 \mu \mathrm{mol}$ ). Similarly, Musk et al. [24] showed the proportion of bakers with a positive methacholine challenge test in less exposed bakers increased from $26 \%$ to $42 \%$ in the more exposed group. BOHADANA et al. [25] reported a significant dose-response relationship with the duration of exposure to flour dust, while CHOUdAT et al. [26] demonstrated that flour dust exposure and smoking increase bronchial responsiveness, as measured by the slope of the dose-response curve to methacholine.

In our population, atopy was identified as an important contributor to nonwork-related asthma as half of these subjects were atopic. This is corroborated by the very high prevalence $(54 \%)$ of a self-reported family history of atopy in the overall study population. Subjects with polysensitisation to common aeroallergens also had a six-fold higher odds ratio of presenting with AA. Among the work-related asthma phenotypes, atopy was significantly associated (OR 4.1) with probable OA but not WAA. This association between atopy and $\mathrm{OA}$ due to high molecular weight sensitisers, such as bakery allergens, has been well documented in the literature [27]. Polysensitised workers were also more likely to be sensitised to occupational allergens (OR 9.5) and present with OA (OR 5.5). This is consistent with the findings of studies among subjects with nonwork-related asthma in adults as well as children, in which only a small proportion of monosensitised individuals become symptomatic when compared with the majority of symptomatic individuals that are polysensitised to common inhalant allergens [28].

In our study of bakery workers, a self-reported history of recurrent chest infections in childhood was a significant predictor (OR 5.5) of only the WAA phenotype. The association between childhood infections and asthma has been previously demonstrated by ARSHAD et al. [29] in their study of children of $10 \mathrm{yrs}$ of age with wheeze and asthma. A more recent study among adults has also demonstrated that having frequent lower respiratory tract infections in childhood is a significant contributory factor in predicting FEV1 decrements in adulthood [30]. Our findings therefore suggest that a history of recurrent infections in childhood could be used as an indicator to identify workers requiring more intensive surveillance, who might be at increased risk of developing WAA. The possibility of recall bias in our study cannot, however, be excluded.

Upper airway symptoms and, more specifically, work-related ocular-nasal symptoms were also significant predictors of AA and OA phenotypes in our study. Previous studies have shown that overall $11.5 \%$ of subjects with occupational rhinitis develop $\mathrm{OA}$, and specifically $11.6 \%$ of those exposed to flours, grains and fodders [31]. Comorbid rhinitis or rhino-conjunctivitis has been reported in a greater proportion $(45-90 \%)$ of subjects suffering from IgE-associated $\mathrm{OA}$ and has been attributable to various sensitisers including flour dust [27]. Interestingly, work-related ocular-nasal symptoms also appear to be an important risk factor for WAA in our study, which, as far as we can establish, has not been previously reported. The cross-sectional nature of our study does not permit conclusions about the temporal relationship of ocular-nasal symptoms and the development of asthma. Overall, however, these findings are consistent with other reported studies in the literature that indicate rhinitis to be a significant risk factor for adult-onset asthma in both work-related and nonwork-related disease outcomes, and that the appearance of ocular-nasal symptoms could be used to identify workers at greater risk of developing OA [31-33].

Self-reported work exposures, particularly episodes of high exposures, can be a useful marker in predicting recent onset adult asthma. In our study, a past history of episodes of high exposure to dusts, fumes and vapours causing asthma symptoms was a significant predictor for WAA and OA phenotypes among bakery workers. Interestingly, a stronger association was observed in workers with WAA (OR 5.8) than those with OA (OR 2.8). This finding is consistent with results from Finland in which $21 \%$ of respondents reported workaggravated symptoms on a weekly basis in the past month in response to a number of factors including airborne dusts, gases or fumes [34]. A recently published ECRHS article also demonstrated an increased asthma risk (OR 3.3) among subjects following acute symptomatic inhalation accidents [3]. These findings suggest that high exposures to sensitisers can contribute substantially to new-onset asthma, and that workers with inhalation accidents should therefore be monitored closely over a longer period of time to identify this entity at an early stage. However, it needs to be borne in mind that 
the definition used in our study, as outlined in the ECRHS protocol, has its limitations as it does not specifically differentiate between flour dust and irritants.

In our study, current job status was a significant predictor of OA in that workers with OA were more likely to be supervisors/ managers (OR 4.0). Although elevated odds ratios were obtained for bakers (OR 1.6), this association was not significant. This is highly indicative of selection effects, as our pilot environmental exposure studies have shown that bakers have much higher exposures to inhalable dust than supervisors/ managers. As the response rate of individual bakeries in our study was high (90-100\%), it is unlikely that nonresponse bias may have affected the results. The "healthy worker effect" is a more likely explanation, in that we have noted that bakers with OA are more likely to be transferred from their high exposure jobs to less exposed jobs (supervisors/managers) rather than the least exposed jobs (counterhands). This is due to the company policy on placement of workers that ensures these bakers, often having the longest service, are retained in the bakery work environment due to their experience, which is then utilised in supervisory and managerial duties.

One of the intriguing findings of our study was the strong association (OR 6.4) between self-reported ingestion-related adverse reactions to grain products and OA phenotype, which was particularly pronounced amongst nonatopic athmatics. The evidence for an association between wheat-related food allergy and baker's asthma is inconclusive. Some studies suggest that inhalant wheat allergy is caused by water-soluble proteins (albumins and globulins) whereas ingestion-related wheat allergy is related to nonwater-soluble, thermo-resistant gluten fractions [35]. Other studies have suggested that similar allergens are responsible for symptoms following both ingestion and inhalation of cereals [36]. MiTTAG et al. [37] demonstrated that subjects with baker's asthma and adults with food allergy had intense IgE-reactivity to both the albumin/globulin and glutenin fraction of wheat proteins [37]. While this may explain the association in the atopic group in our study, it is possible that the stronger associations observed in the nonatopic group may be due to other factors, such as water-insoluble proteins (wheat gliadins) [38], or nonimmune reactions, such as gluten intolerance. Further studies are currently being conducted to evaluate this differential response between atopic and nonatopic asthmatics with $\mathrm{OA}$ and ingestion-related reactions to grain products, as this may have important implications for dietary counselling of workers with OA.

In conclusion, our study has demonstrated that OA is the most common asthma phenotype among supermarket bakery workers in this region and is an important globally evolving trend. Analysis of risk factors contributes towards differentiating between these various phenotypes. Defining various clinical phenotypes using specific clinical criteria is important for decisions regarding medical surveillance and clinical management of this high-risk group. Medical surveillance programmes in bakeries can therefore use these criteria to identify persons at risk at an early stage and intensify surveillance and other workplace interventions. Furthermore, in view of the increase in baking activities in supermarkets globally, measures to monitor and reduce exposures remain an important priority.

\section{SUPPORT STATEMENT}

Funding support was provided by research grants from the Medical Research Council of South Africa (Cape Town), National Research Foundation (Pretoria), Fogarty International Centre (Bethesda, MD, USA), the Allergy Society of South Africa (Cape Town) and University of Cape Town Research Committee (Cape Town) and the baking industry (Cape Town).

\section{STATEMENT OF INTEREST}

A statement of interest for D. Heederik can be found at www.erj. ersjournals.com $/ \mathrm{misc} /$ statements.dtl

\section{ACKNOWLEDGEMENTS}

We would like to acknowledge the special contribution of the following individuals and institutions. R. Ehrlich and J. Myers and support staff of the Centre for Occupational and Environmental Health Research Unit, School of Public Health and Family Medicine, University of Cape Town. Research assistants, N. Viljoen and L. Ritchie, and F. Omar in conducting the fieldwork from the Centre for Occupational and Environmental Health Research Unit. V. Barnard, A. Olckers and technologists from the Dept of Respiratory Medicine and Lung Institute, University of Cape Town Lung Institute, for the pulmonary function and methacholine challenge testing. J. van Niekerk for data entry and management and R. Sayed and F. Little, from the Depts of Public Health and Statistical Sciences, University of Cape Town, for statistical advice and support. The contents of our report are solely the responsibility of the authors and do not necessarily reflect the official views of these agencies. We would also like to acknowledge the staff and employees of the bakeries that participated in this study.

\section{REFERENCES}

1 Brisman J. Baker's asthma. Occup Environ Med 2002; 59: 498-502.

2 Wenzel SE. Asthma: defining of the persistent adult phenotypes. Lancet 2006; 368: 804-813.

3 Kogevinas M, Zock JP, Jarvis D, et al. Exposure to substances in the workplace and new-onset asthma: an international prospective population-based study (ECRHS-II). Lancet 2007; 370: 336-341.

4 Brant A, Berriman J, Sharp C, et al. The changing distribution of occupational asthma: a survey of supermarket bakery workers. Eur Respir J 2005; 25: 303-308.

5 Erasmus JC, Cownie PJ. Investigation into the development of small and medium sized bakeries in South Africa. Human, Sciences Research Council \& South African Chamber of Baking, Employment and Economic Policy Research Unit, Pretoria, South Africa 2002.

6 Burney PG, Luczynska C, Chinn S, et al. The European Community Respiratory Health Survey. Eur Respir J 1994; 7: 954-960.

7 Aas K, Belin L. Standardization of diagnostic work in allergy. Int Arch Allergy Immunol 1973; 45: 57-60.

8 American Thoracic Society, Standardization of spirometry - 1994 update. Am J Respir Crit Care Med 1995; 152: 1107-1136.

9 Quanjer PH, Tammeling GJ, Cotes JE, et al. Lung volumes and forced ventilatory flows. Report Working Party Standardization of Lung Function Tests, European Community for Steel and Coal. Official Statement of the European Respiratory Society. Eur Respir J 1993; 6: Suppl. 16, 5-40.

10 White NW, Hanley JH, Lalloo UG, et al. Review and analysis of variation between spirometric values reported in 29 studies of healthy African adults. Am J Respir Crit Care Med 1994; 150: 348-355.

11 American Thoracic Society. American Thoracic Society (ATS) Guidelines for Methacholine and Exercise Challenge Testing 1999. Am J Resp Crit Care Med 2000; 16: 309-329.

12 Beach J, Russell K, Blitz S, et al. A systematic review of the diagnosis of occupational asthma. Chest 2007; 131: 569-578. 
13 Variations in the prevalence of respiratory symptoms, self reported asthma attacks, and use of asthma medication in the European Community Respiratory Health Survey (ECRHS). Eur Respir J 1996; 9: 687-695.

14 Ehrlich R I, White N, Norman R, et al. Wheeze, asthma diagnosis and medication use: a national adult survey in a developing country. Thorax 2005; 60: 895-901.

15 Jithoo A, Bateman ED, White NW, et al. Prevalence of adult lung disease in a middle-to-low income urban area of South Africa: Lung Health Survey 2002 (Abstract). S Afr Respir J 2003; 9: 127.

16 Pearce N, Pekkanen J, Beasley R. How much asthma is really attributable to atopy? Thorax 1999; 54: 268-272.

17 Pavlovic M, Spasojevic M, Tasco Z, et al. Bronchial hyperactivity in bakers and its relation to atopy and skin reactivity. Science of the Total Environ 2001; 270: 71-75.

18 De Zotti R, Larese F, Bovenzi M, et al. Allergic airway disease in Italian bakers and pastry makers. Occup Environ Med 1994; 51: 548-552.

19 Gautrin D, Infante-Rivard C, Dao TV, et al. Specific IgE-dependent sensitization, atopy, and bronchial hyperresponsiveness in apprentices starting exposure to protein-derived agents. Am J Respir Crit Care Med 1997; 155: 1841-1847.

20 DunnGalvin A, Hourihane JO, Frewer L, et al. Incorporating a gender dimension in food allergy research: a review. Allergy 2006; 61: 1336-1343.

21 Sandiford CP, Tee RD, Newman-Taylor AJ. Identification of cross reacting wheat, rye, barley and soya flour allergens using sera from individuals with wheat-induced asthma. Clin Exp Allergy 1995; 25: 340-349.

22 Bensefa L, Villette C, Tabka F, et al. Rye flour induces a stronger early bronchial response than wheat flour in occupational asthma. Allergy 2004; 59: 833-838.

23 Prichard MG, Ryan G, Musk AW. Wheat flour sensitisation and airways disease in urban bakers. Br J Ind Med 1984; 41: 450-454.

24 Musk AW, Venables KM, Crook B, et al. Respiratory symptoms, lung function, and sensitisation to flour in a British bakery. Br J Ind Med 1989; 46: 636-642.

25 Bohadana AB, Massin N, Wild P, et al. Respiratory symptoms and airway responsiveness in apparently healthy workers exposed to flour dust. Eur Respir J 1994; 7: 1070-1076.
26 Choudat D, Bensefa L, Causse-Sounillac E, et al. Methacholine bronchial responsiveness and variations in lung function among workers exposed to flour. Scand I Work Environ Health 2005; 31: 59-64.

27 Nicholson PJ, Cullinan P, Newman Taylor AJ, et al. Evidence based guidelines for the prevention, identification, and management of occupational asthma. Occup Environ Med 2005; 62: 290-299.

28 Bousquet J, Anto JM, Bachert C, et al. Factors responsible for differences between asymptomatic subjects and patients presenting an IgE sensitization to allergens. A GA ${ }^{2} \mathrm{LEN}$ project. Allergy 2006; 61: 671-680.

29 Arshad SH, Kurukulaaratchy RJ, Fenn M, et al. Early life risk factors for current wheeze, asthma and bronchial hyperresponsiveness at 10 years of age. Chest 2005; 127: 502-508.

30 Tennant PWG, Gibson GJ, Pearce MS. Lifecourse predictors of adult respiratory function: results from the Newcastle Thousand Families Study. 2008; 63: 823-830.

31 Karjalainen A, Martokainen R, Klaukka T, et al. Risk of asthma among Finnish patients with occupational rhinitis. Chest 2003; 123: 283-288.

32 Elliot L, Heederik D, Marshall S, et al. Progression of self-reported symptoms in laboratory animal allergy. J Allergy Clin Immunol 2005; 116: 127-132.

33 Guerra S, Sherrill DL, Martinez FD, et al. Rhinitis as an independent risk factor for adult-onset asthma. J Allergy Clin Immunol 2002; 109: 419-425.

34 Saarinen K, Karjalainen, Martikainen R, et al. Prevalence of workaggravated symptoms in clinically established asthma. Eur Respir J 2003; 22: 305-309.

35 Moneret-Vautrin DA, Morisset M. Adult food allergy. Curr Allergy Asthma Rep 2005; 5: 80-85.

36 Armentia A, Rodriques R, Callejo A, et al. Allergy after ingestion or inhalation of cereals involves similar allergens in different ages. Clin Exp Allergy 2002; 32: 1216-1222.

37 Mittag D, Niggemann B, Sander I, et al. Immunoglobulin Ereactivity of wheat-allergic subjects (baker's asthma, food allergy, wheat-dependent, exercise-induced anaphylaxis) to wheat protein fractions with different solubility and digestibility. Mol Nutr Food Res 2004; 48: 380-389.

38 Bittner C, Grassau B, Frenzel K, et al. Identification of wheat gliadins as an allergen family related to baker's asthma. J Allergy Clin Immunol 2008; 121: 744-749. 